\title{
Author Correction: Intensification of terrestrial carbon cycle related to El Niño-Southern Oscillation under greenhouse warming
}

\author{
Jin-Soo Kim (iD ${ }^{1}$, Jong-Seong Kug (iD ${ }^{1}$ \& Su-Jong Jeong ${ }^{2}$
}

Correction to: Nature Communications https://doi.org/10.1038/s41467-017-01831-7, Article published online 22 November 2017

In the original version of this Article, the affiliation for Su-Jon Jeong was incorrectly given as 'Southern University of Science and Technology of China (SUSTECH)', instead of 'Southern University of Science and Technology (SUSTECH)'. This has now been corrected in both the PDF and HTML versions of the Article.

Published online: 15 January 2018

\begin{abstract}
(c) (i) Open Access This article is licensed under a Creative Commons Attribution 4.0 International License, which permits use, sharing, adaptation, distribution and reproduction in any medium or format, as long as you give appropriate credit to the original author(s) and the source, provide a link to the Creative Commons license,

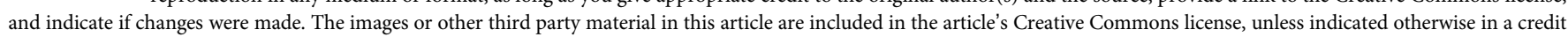

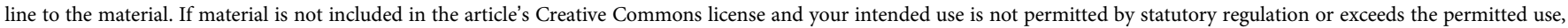
you will need to obtain permission directly from the copyright holder. To view a copy of this license, visit http://creativecommons.org/licenses/by/4.0/.
\end{abstract}

(C) The Author(s) 2018

\footnotetext{
${ }^{1}$ Division of Environmental Science and Engineering, Pohang University of Science and Technology (POSTECH), Pohang, 37673, South Korea. ${ }^{2}$ School of Environmental Science and Engineering, Southern University of Science and Technology (SUSTECH), Shenzhen, 518055, China. Correspondence and requests for materials should be addressed to J.-S.K. (email: jskug@postech.ac.kr) or to S.-J.J. (email: sujong@sustc.edu.cn)
} 